\title{
Confronting Sexual Violence Through Dance and Theatre Pedagogy
}

\author{
Doris Rajan, Roshanak Jaberi, and Shahrzad Mojab
}

\begin{abstract}
AвSTRACT The historically-shaped violence embedded in ongoing relations of colonization and imperialism for both refugee and Indigenous women across the globe are stories mostly told in reports and statistics. The performance-based art forms of theatre and dance can enhance knowledge sharing, build relationships and assist women in a deeper understanding of their realities. In pursuit of an effective use of these art forms; however, scripted stories need to ensure that women who experience oppression, formulate the storytelling. In addition, the enactment and representation should share women's material histories in order to contextualize experiences in terms of specific relations to land, war, violence, displacement and dispossession. Using the two case studies of Doris Rajan's play, A Tender Path and Roshanak Jaberi's multidisciplinary dance project, No Woman's Land, this article examines how community-engaged research and performance arts-based approaches can be used to challenge and provoke our ways of understanding and thinking about how to disrupt and alter oppressive relat
\end{abstract}

KEYWORDS Refugees, Indigenous peoples, violence against women, art-based research, community-engaged scholarship

The three of us are engaged in a unique collaboration: Doris Rajan is a community organizer/ educator as well as a theatre and film artist, Roshanak Jaberi a multidisciplinary dance artist, and Shahrzad Mojab, an academic, activist and educator. What has brought us together is our desire to address structural violence against women as well as our belief in the power of performance art in building awareness and challenging our ways of understanding. This article examines two case studies of performance art presentations that were inspired by real stories recounted through a community-based research process. Rajan's $A$ Tender Path, a theatrical play and Jaberi's No Woman's Land, a multidisciplinary dance production. Both cases attempt to engage audiences with the issues of oppression and violence that refugee and Indigenous women experience in their lives as they go through displacement, dispossession, and arrive at 'resettlement' or confront settler colonialism. This article provides some reflections on the research and creation process for both art pieces, as they relate to performance art pedagogy in pursuit of learning about structural violence against refugee and Indigenous women.

We seek the root of structural violence in the disarticulation of the relationship between patriarchy, race, class and capitalism. The prevalent conceptualization of violence against 
women focuses on the individual's experience, paying less attention to how power operates and the ways in which violence is embedded in institutions and structures of society-particularly for refugee and Indigenous women. Without challenging the complex matrix of forces that (re)produce inequalities or the ways in which "penalty and privilege" (Collins, 1990) operate, anti-violence strategies will have minimal impact on restructuring institutions or reforming social policy. This limitation is related to the dynamic of interventions which often fail to get to the core of violence production in ways that can transform broader social relations and systems that reproduce and maintain violence.

Our conceptualization of violence and its perpetual reproduction of power has implications on how we have approached the research process and how each performance piece developed its own artistic narrative. For example, Rajan's research on solidarity learning as reflected in her play $A$ Tender Path, recognizes that each marginalized group has a different relationship with the colonial Canadian state. Further, to engage in a decolonized pedagogy, it is necessary to spend the time listening and learning about our different histories, experiences, and dreams. The play $A$ Tender Path set out to provide the setting to learn about these different histories and current day manifestations of oppression and violence. Jaberi's No Woman's Land aims to share the experiences of women who live in refugee camps through movement and the use of some spoken text in ways that present women not as victims, but as survivors who face their violent and forced circumstances with strength and resilience.

We know that theatre and dance do not offer intricate strategies to dismantle complex, historically entrenched systems of oppression; however, we believe they can serve the purpose of initiating a process of learning about history, process of displacement, dispossession, and forms of resistance and learning. We have realized that storytelling is a powerful method for revealing the detail and nuances of often concealed experiences. This is what both Rajan and Jaberi have been attempting to do with their art forms, supported by the research expertise facilitated by Mojab. Rajan was specifically commissioned to write $A$ Tender Path with the explicit purpose of sharing the experiences of refugee and Indigenous women in ways that would draw us into the issues beyond abstract engagement, towards a more visceral, emotive experience. In 2014 Rajan was approached by the Community Inclusivity Equity Council, a coalition of community workers and activists in York Region, Ontario organizing a national and international event entitled the Truth, Reconciliation, and Engagement Symposium, to develop a theatrical piece for their three-day initiative that occurred in April 2015. The Symposium focused on service provision to diverse individuals, families and communities who have experienced traumatic events. The purpose of the theatre initiative was to provide a different technique at the Symposium to explore the issues experienced by communities/individuals impacted by trauma, specifically the Chippewa First Nation of Georgina Island, the Transgender communities, and refugee communities in Canada. The play offered a new vantage point for provoking a dialogue between Indigenous, racialized, and refugee or migrant people-mostly women — and other populations who have experienced acute oppression. The developmental process for the play involved research and consultation with the target communities and the engagement of theatre

Engaged Scholar Journal: Community-Engaged Research, Teaching and Learning 
professionals to bring it to the stage, i.e., a director, a dramaturge, and professional actors. ${ }^{1}$ During the writing process, Rajan was simultaneously reading Out of the Depths (Knockwood \& Thomas, 1992) in Mojab's Memoir Pedagogy Reading Circle. The character Isabelle of this autobiographical account, steadfastly walks us through pages of detailed horror experienced by Mi'kmaw children in the residential school system. The character of Isabelle became key to the framing of the play as she spoke to and supported the pain of others, i.e., two refugee women, a woman with an intellectual disability, and a Trans woman throughout the course of the storyline.

After the performance we opened it up to questions and comments from the audience composed of disability, Indigenous, Trans, anti-racist and immigrant and refugee community members and activists. The result was that people were surprised and shocked about how little they knew about the 'others' experience. For example, a long-time Tamil refugee rights activist, a refugee herself having lived in Canada for over 30 years, never knew about the violence and pain of the residential school experience for Indigenous peoples. After the show she said to the audience, "I want this play to be translated into Tamil so our people can learn and understand" (P. Kanthasamy, personal communication, April 28, 2015). This was a sign of success and a crucial first step in solidarity building with these populations. We learned that: (a) by centering the work on real stories and translating those stories to live performance, previously unknown stories became known; (b) by using theatre professionals the play was successful in communicating the authenticity and realness of the diverse experiences, enhanced by the immediacy of gaining access to private moments and thoughts; (c) marginalized people were put side by side for one hour and the audience, not only saw themselves, but witnessed solidarity in action as characters supported one another in the recollection of painful memories; and (d) the stories were not individualized - that is, they were contextualized in histories of colonization and contemporary capitalist wars.

Jaberi's interest in socially charged dance work is rooted in her 2010 project Behind the Stained Walls, which is based on the real stories of Iranian political prisoners. In 2009, she was introduced to Mojab at the University of Toronto who helped guide her research through interviews with former political prisoners who are settled in Canada, as well as prison memoirs and the testimonies of survivors. Behind the Stained Walls helped deepen Jaberi's artistic practice and was the impetus behind her commitment to creating political art. The project also helped steer her research and formed the foundation of her creative process for No Woman's Land, her most recent project, which explores the issue of violence against women in refugee camps. This three-year initiative looks at the lived experiences of refugee women and addresses the impact of displacement by looking at the pre-migration and post migration experiences. Jaberi uses dance as a point of entry into the creation of the work and augments the narrative with verbatim theatre, poetry and multi-media. She also draws on her personal experiences

\footnotetext{
${ }^{1}$ To learn more about the cast and crew please see Dinner and Theatre Event - A Tender Path - Presented by Community Inclusivity Equity Council of York Region (CIECYR). Retrieved from: http://parkbench.com/event/dinner-and-theatreevent-a-tender-path-presented-by-community-inclusivity-equity-council-of-york-region-ciecyr
} 
as a former refugee and survivor of war to look at the long-term impacts of trauma to both inform those who have no connection to these experiences and enable those who do.

Theatre and dance can serve to encourage those who feel powerless and instill a sense of control over one's own world by provoking understandings of the "root causes of problems and oppression" and to "give voice and expression" to these understandings (Boon \& Plastow, 2004, p. 7). Performance art can support oppressed communities to reclaim their identities by the presentation of their "ignored histories" (Boon \& Plastow, 2004, p. 11). Therefore, while theatre and dance may not offer intricate strategies to dismantle systems of oppression, they can serve the purpose of initiating a process of deeper understanding of self within the social and historical realities:

Empowerment is to do not with the amelioration of oppression and poverty per se, but with the liberation of the human mind and spirit, and the transformation of participants who see themselves - and are often seen by others-as subhuman, operating only at the level of seeking merely to exist, into conscious beings aware of and claiming voices and choices in how their lives will be lived. (Boon \& Plastow, 2004, p. 7)

It is evident through our own practice that dance and theatre can have an impact in building relationships towards inspiring social change; however, we are trying to understand how or why these art forms have the impact that they do. These art mediums allow us to learn through metaphors, transmitting knowledge visually and through text, which offers a more immediate connection to our emotional centres (Sealey, 2008, p. 3). Theatre and dance can also assist us to visualize "situations in concrete terms" which also brings an immediacy to the happenings which we witness as spectators (Sealey, 2008, p. 119). The tangible and immediate nature of a live performance offers the viewer alternative ways of thinking that "transcends an abstract intellectual approach" (Sealey, 2008 p. 120). The physicality of being present in a theatre where live performances occur, asserts our "physical taking of space" and "inscribes the body as a powerful site of empowerment” (Boon \& Plastow, 2004, p. 11). When pedagogy seeks to actuate critical thinking, it aims to assist individuals and groups to problematize their reality towards the development of capacities that pursue "both their own and society's liberation" (Kellner \& Kim, 2010, p. 3). Dance and theatre can trigger both emotions and new ways of thinking to facilitate understanding in both an embodied and intellectual manner. Dance and theatre does this by offering "visual literacy" that can draw the viewer into "discussion and debate" using "the clarity of a visual image as the catalyst" (Sealey, 2008, p. 7). Our job therefore as researchers, activists, theatre and dance creators is to attempt to summon and move "feeling to thinking" which can result in "changed relation to the self and others" (Tarc, 2011, p. 365). More specifically, emotions activated by dance and theatre can "sharpen" our "critical thinking skills" in ways that expand our choices and help us examine and question our "normalized assumptions" (Sealey, 2008, p. 63).

Therefore, the content development process is very important in a dance or theatre

Engaged Scholar Journal: Community-Engaged Research, Teaching and Learning 
pedagogy for social change. The process needs to leverage the power of the crafts, i.e., in terms of how we tell a story, the visual vocabulary, use of movement, text and dialogue, character development and music, in a manner which is aligned to our social change and justice goals. We contend that in this process the first step is to attain a solid understanding of the social problem, for example the distinct manifestations of violence experienced by each women's group and their ideas around how to confront it.

Next, the material histories of people, their lived realities, should be shared to ensure that issues are contextualized and/or are understood in terms of specific relations, political influences and broader socio-economic issues. Therefore, we have found that the pedagogic use of dance and theatre needs to go beyond assumptions and be grounded in sound research about the target audience if it is to be successful in influencing activism. Thus, a clear understanding of the history and present-day conflict facing Indigenous and refugee women is essential before translating these experiences to individual stories using movement or text narratives.

For example, Jaberi draws on individual stories to highlight larger and more complex issues of systemic violence and oppression, which carry a sense of urgency and necessity. She believes that both artists and audiences have a responsibility in their relationship to the creation and viewership of the work. In this sense art can be viewed as a privilege and one that requires truthfulness on stage, which at times requires the evoking of uncomfortable images. As such, the audience's responsibility is closely related to the artist's contextual framing of the story in the developmental process. Gratuitous violence on stage, for instance, does not serve a pedagogical purpose yet art work that denies the truth of survivors to make the experience more palatable for audiences of a dominant culture demonstrates how power has disrupted the authentic narrative.

The developmental process for $A$ Tender Path involved the engagement of Tamil, Somali, Iranian, Trans, Indigenous, and disability rights community-based researchers who organized and facilitated focus groups. ${ }^{2}$ Recorders were asked to document as much in verbatim as possible. This helped Rajan, as the playwright, to become familiar with specific types of words that were used to describe a situation, to express difficult issues, or to present ideas that excited them and/or the different types of body language that would emerge.

Jaberi approached Mojab and Rajan to learn more about the issue of violence against marginalized women, particularly refugee women. Rajan was tasked with leading the primary research process, which was comprised of focus group sessions conducted with women from Tamil, Syrian, and Somali communities in Toronto. These three groups were selected based on their history of conflict and resulting refugee and migrant experiences prior to settlement in Canada. Similar to the research process for $A$ Tender Path, community-based researchers were engaged to lead in the facilitation process in their own languages. The process involved the development of discussion guides which were vetted at a train-the-trainer session with the community facilitators prior to conducting the focus groups. The purpose of this session

${ }^{2}$ Some of these focus groups were held in the women's own languages, and therefore the materials were translated to English. 
was to ensure that the stories were collected and recorded in an ethical manner. In addition, at this session facilitators learned about the type of information sought-how women feel about difficult situations they were in, getting a sense of movement and setting, etc.any information that could be easily translated to dance. The train-the-trainer session also provided the opportunity to seek the input of the community facilitators regarding the most culturally appropriate and sensitive ways to carry out the focus group sessions. For some of the communities of women it was more appropriate to gather the information while doing something, e.g., a cooking session or over tea at a community centre that they visit regularly.

The stories for No Woman's Land were based on an extensive literature review of the experiences of sexual violence of Somali, Tamil, Syrian, and Palestinian women who lived in refugee camps. This process included the development of a final report, which detailed the findings of the research as it pertained to the issue of sexual violence for each of these women's groups as they transited through refugee camps. Transcripts from the focus groups as well as the report on the literature served to inform the artistic direction of production. The challenging task of translating these stories through movement, required a cast of open and generous performers who were willing to be vulnerable and were committed to delving into the research that was shared in the studio. Jaberi's process included extracting images and stories that resonated with her, and this was used as the starting point to develop the overarching narrative and choreography.

It is important to note that the participants of the focus groups for both of the art pieces, were viewed as collaborators and not merely as subjects of the project. Therefore, engaging the participants through the entire process is an essential component of the work. It has also been vital to take the time to pause, reflect and consult at various junctions in the development of the work to ensure that the stories that were so generously shared had not been compromised by taking too much artistic liberty. On the other hand, creating some distance from the research has been necessary to allow for creative freedom. The ultimate goal of social-justice motivated performance art is to create work that is emotive, evocative, and thought provoking and not a literal representation of the content that is being explored. The production is intended to serve as a springboard to further the discussion around the refugee experience and gender-based violence in racialized communities, as well as to bring the focus back to the women at the heart of this complex systemic issue.

To sum up, a well-constructed performance art pedagogy develops stories that avoid didactic simplifications and leaves room for what the theatre or dance maker does not know, i.e., to present stories where many interpretations of the truth can emerge. In fact, critical discourse translated to these art forms can change how we understand and see social circumstances by offering alternative narratives. The pedagogical use of dance and theatre to assist in social change strategies will need to contain information that is based on critical theory and understandings grounded in real experiences. We can see that dance and theatre tools should be carefully and strategically constructed in order to effectively support the individual's and group's capacity to understand their oppression.

Engaged Scholar Journal: Community-Engaged Research, Teaching and Learning 


\section{About the Authors}

Roshanak Jaberi is a performer, choreographer, and producer, and the Artistic Director of Jaberi Dance Theatre, a contemporary dance company that creates inter-disciplinary work with socio-political content. She also serves on the Toronto Arts Council Dance Committee and is an executive board member of the Dance Umbrella of Ontario.

Shahrzad Mojab is a scholar, teacher, and activist, internationally known for her work on the impact of war, displacement, and violence on women's learning and education. She is professor of Adult Education and Women and Gender Studies at the University of Toronto. She is the former Director of the Women and Gender Institute, and the recipient of the Royal Society of Canada Award in Gender Studies in 2010.

Doris Rajan (corresponding author) is the Director of Social Development at the Institute for Research and Development on Inclusion and Society, as well as a $\mathrm{PhD}$ candidate at the University of Toronto. Her work focuses on violence against marginalized women and involves designing social development/applied research projects. Doris is also an actress, playwright, screenwriter, and filmmaker. Email: d.rajan@irisinstitute.ca

\section{References}

Boon, R., \& Plastow, J. (2004). Theatre and empowerment: Community drama on the world stage. Cambridge, UK: Cambridge University.

Collins, P.H.. (1990). Black feminist thought: Knowledge, consciousness, and the politics of empowerment. Boston, MA: Unwin Hyman.

Kellner, D., \& Kim, G. (2010). YouTube, critical pedagogy, and media activism. The Review of Education, Pedagogy, and Cultural Studies, 32(1), 3-36.

Knockwood, I., \& Thomas, G. (1992). Out of the depths: The experiences of Mi'kmaw children at the Indian Residential School at Shubenacadie, Nova Scotia. Lockeport, N.S.: Roseway.

Sealey, K. S. (2008). Film, politics, \& education: Cinematic pedagogy across the disciplines. New York, NY: Peter Lang.

Tarc, A. M. (2011). Reparative curriculum. Curriculum Inquiry, 41(3), 350-372. 